\title{
Characterization of Phase Chemistry and Partitioning in a Family of High-Strength Nickel-Based Superalloys
}

\author{
M.T. LAPINGTON, D.J. CRUDDEN, R.C. REED, M.P. MOODY, and P.A.J. BAGOT
}

\begin{abstract}
A family of novel polycrystalline Ni-based superalloys with varying $\mathrm{Ti}: \mathrm{Nb}$ ratios has been created using computational alloy design techniques, and subsequently characterized using atom probe tomography and electron microscopy. Phase chemistry, elemental partitioning, and $\gamma^{\prime}$ character have been analyzed and compared with thermodynamic predictions created using Thermo-Calc. Phase compositions and $\gamma^{\prime}$ volume fraction were found to compare favorably with the thermodynamically predicted values, while predicted partitioning behavior for $\mathrm{Ti}, \mathrm{Nb}$, $\mathrm{Cr}$, and Co tended to overestimate $\gamma^{\prime}$ preference over the $\gamma$ matrix, often with opposing trends $v s$ $\mathrm{Nb}$ concentration.
\end{abstract}

https://doi.org/10.1007/s11661-018-4558-7

(c) The Author(s) 2018

\section{INTRODUCTION}

NiCKEL-BASED superalloys are widely used in the high-pressure section of gas turbine engines due to their exceptional oxidation resistance and strength at temperatures up to and exceeding $1000{ }^{\circ} \mathrm{C}^{[1,2]}$ Commercial and environmental drivers seek to increase turbine operating temperatures, requiring further alloy optimization in order to satisfy the increasing demands on strength and oxidation resistance. Complex trade-offs have to be considered in order to retain these properties alongside fatigue resistance, creep resistance, and phase stability during the optimization process. ${ }^{[3]}$ Much of the high-temperature strength of these alloys come from the precipitation of fully coherent ordered FCC $\gamma^{\prime}$ phase precipitates. ${ }^{[4]}$ These precipitates retain strength at high temperatures via their unique ability to resist deformation by promoting cross slip of partial dislocations onto locked planes. ${ }^{[5]}$ This deformation mechanism is heavily influenced by $\gamma^{\prime}$ volume fraction and chemistry, as $\gamma^{\prime}$ forming elements such as $\mathrm{Ti}$, $\mathrm{Ta}$, and $\mathrm{Nb}$ have been shown to increase strength by raising the stacking fault energy at anti-phase boundaries (APB) found in the ordered precipitates. ${ }^{[6,7]}$ However, there are limits regarding the addition of $\gamma^{\prime}$ forming elements, as high

M.T. LAPINGTON, M.P. MOODY and P.A.J. BAGOT are with the Department of Materials, University of Oxford, Parks Road, Oxford OX13PH, UK. Contact e-mail: mark.lapington@materials. ox.ac.uk D.J. CRUDDEN is with the Department of Engineering Science, University of Oxford, Parks Road, Oxford OX1 3PJ, UK. R.C. REED is with the the Department of Materials, University of Oxford and also with the Department of Engineering Science, University of Oxford.

Manuscript submitted November 28, 2017.

Article published online March 13, 2018 $\gamma^{\prime}$ volume fraction has been shown to have detrimental effects on processing and fatigue resistance, ${ }^{[8,9]}$ while addition of $\mathrm{Nb}$ and $\mathrm{Ti}$ can adversely affect $\gamma^{\prime}$ phase stability due to their potential to form deleterious secondary phases such as $\delta\left(\mathrm{Ni}_{3} \mathrm{Nb}\right)^{[10]}$ or $\eta\left(\mathrm{Ni}_{3} \mathrm{Ti}\right) .^{[11,12]}$ Ti has also been previously shown to reduce oxidation resistance in model Ni-Cr-Ti polycrystalline alloys. ${ }^{[13,14]}$

Optimization of $\mathrm{Ti}$ and $\mathrm{Nb}$ levels is therefore necessary in order to find an appropriate balance between high-temperature strength, oxidation resistance, and phase stability. Recent advances in computational optimization techniques have utilized thermodynamic modeling to predict phase chemistries and physical properties based on composition alone, resulting in major cost and time savings. The Alloys-by-Design (ABD) process developed by Reed et al. ${ }^{[15]}$ utilizes a set of merit-indices to sort through these compositions looking to balance the trade-offs mentioned above. This ABD process has been modified for application to polycrystalline superalloys by Crudden et al. ${ }^{[16]}$ which has been used to create a family of superalloys to investigate composition-property relationships, with a focus on the effect of $\mathrm{Ti}$ and $\mathrm{Nb}$ on microstructure and phase chemistry as they relate to oxidation resistance and high-temperature strength.

The small size of $\gamma^{\prime}$ precipitates and need for accurate phase chemistry determination requires a quantitative analysis technique with high spatial resolution and elemental sensitivity. Atom probe tomography (APT) combines both of these with powerful 3D analysis capabilities, ${ }^{[17]}$ and has been successfully used in the past $^{[18-21]}$ to investigate phase chemistries ${ }^{[22-24]}$ and partitioning ratios ${ }^{[25]}$ in nickel-based superalloys. The high spatial resolution and $3 \mathrm{D}$ analysis also allows 
detailed investigation of nanoscale tertiary $\gamma^{\prime}$ precipitates, as well as $\gamma-\gamma^{\prime}$ interfaces. ${ }^{[26]}$

\section{MATERIALS AND METHODS}

To study the effect of varying $\mathrm{Ti}: \mathrm{Nb}$ ratio, a family of superalloys has been created which are near identical in composition, except for the substitution of $\mathrm{Nb}$ for $\mathrm{Ti}$ on a 1:1 basis. This similarity of composition between the alloys allows direct comparisons of microstructure and chemistry to be made. The target alloy compositions ${ }^{[27]}$ given in Table I result from using the ABD method to predict compositions with high strength at $800{ }^{\circ} \mathrm{C}$ combined with good oxidation resistance. The material that was examined in this investigation was extracted from pancake forgings, which were isothermally forged from hot isostatic pressed powder. The as-manufactured alloy compositions are also provided in Table I, which were measured using a combination of X-ray fluorescence (XRF) spectroscopy, the combustion infra-red method and inductively coupled plasma-optical emission spectroscopy (ICP-OES). A two-stage super-solvus heat treatment was carried out, including $\gamma^{\prime}$ solutionizing at $1170{ }^{\circ} \mathrm{C}$ for 2 hours followed by aging at $850{ }^{\circ} \mathrm{C}$ for 4 hours.

Metallographic samples for SEM analysis were sectioned using an Isomet 5000 diamond cutting wheel, then ground and polished with successively finer grades of $\mathrm{SiC}$ grit paper and diamond suspension. A mirror finish was achieved using $0.06 \mu \mathrm{m}$ COL-K colloidal silica, and no subsequent etching was performed. SEM images have been captured using a Zeiss Nvision 40 FIB-SEM with $5 \mathrm{kV}$ beam current to a maximum magnification of 20,000 times, using the inlens secondary electron detector to enhance the visual contrast between $\gamma$ and $\gamma^{\prime}$ phases. Image J software ${ }^{[28]}$ has been used to process the SEM images and calculate the cross-sectional area and size distribution of $\gamma^{\prime}$ precipitates.

Sample blanks for atom probe tomography were cut from sections of superalloy into $0.5 \mathrm{~mm} \times 0.5 \mathrm{~mm} \times$ $20 \mathrm{~mm}$ cuboidal rods. A two-stage electropolishing process was used to create needle-shaped samples with a tip diameter $<100 \mathrm{~nm},{ }^{[17]}$ with 25 pct perchloric acid solution (in acetic acid) at a voltage of $16 \mathrm{~V}$ for first-stage shaping, and 2 pct perchloric acid solution (in butoxyethanol) at a voltage of $10 \mathrm{~V}$ for second stage polishing. Specimens were analyzed in a Cameca LEAP 3000X $\mathrm{HR}$ in laser-pulsing mode, at a pulse frequency of $200 \mathrm{MHz}$, laser pulse energy between 0.4 and $0.5 \mathrm{~nJ}$, and a stage temperature of $50 \mathrm{~K}$. Detection rates (the average percentage of pulses resulting in ion detection) were targeted around 2 pct in order to maximize yield. All atom probe data have been reconstructed and analyzed using Cameca IVAS 3.6.12 software. Peaks observed in the mass spectra were ranged using a background-to-background ranging technique, with each individual range spectra templated from a universal ABD-superalloy range file to ensure consistency. The freely available APTtools software suite ${ }^{[29,30]}$ was routinely referenced to ensure that elemental peak signatures identified during ranging are accurate and complete. Peak overlaps consisting of multiple elemental species have been deconvolved using standard IVAS decomposition parameters, which helps to maintain quantitative composition accuracy at the potential cost of spatial information. Phase compositions were measured using $10 \mathrm{~nm} \times 10 \mathrm{~nm} \times 10 \mathrm{~nm}$ volumes located far from phase boundaries. The average composition of two volumes was used to calculate matrix composition (16 volumes totalling $5.5 \times 10^{5}$ ions), and $\gamma^{\prime}$ precipitate compositions were given as a weighted average of all precipitates in the sample (32 volumes totalling $5.9 \times 10^{5}$ ions).

Thermodynamic modeling was carried out in Thermo-Calc 2015b using the TTNi8 (Thermo-Tech) and TCNi8 (Thermo-Calc) databases. Phase composition calculations were based on the as-manufactured compositions, and performed at the final alloy aging temperature of $850{ }^{\circ} \mathrm{C}$. The superalloys have been assumed to be in a 3-phase system consisting of $\gamma, \gamma^{\prime}$ and MC carbides, which were the only phases observed at room temperature during $\mathrm{X}$-ray synchrotron experiments, ${ }^{[31]}$ with all other phases suspended.

Table I. Target and Measured Compositions (Atomic Percent) of ABD Series Superalloys Investigated in This Study

\begin{tabular}{|c|c|c|c|c|c|c|c|c|c|c|c|c|c|}
\hline Alloy & $\mathrm{Ni}$ & $\mathrm{Cr}$ & $\mathrm{Co}$ & $\mathrm{W}$ & $\mathrm{Al}$ & $\mathrm{Ti}$ & $\mathrm{Ta}$ & $\mathrm{Nb}$ & $\mathrm{C}$ & $\mathrm{B}$ & $\mathrm{Zr}$ & $\mathrm{Fe}$ & $\mathrm{Si}$ \\
\hline \multicolumn{14}{|l|}{ ABD-2 } \\
\hline Target & 49.2 & 18.7 & 18.2 & 0.9 & 8.0 & 4.1 & 0.6 & 0.0 & 0.13 & 0.08 & 0.04 & - & - \\
\hline Measured & 48.5 & 18.9 & 18.5 & 1.0 & 7.9 & 4.3 & 0.7 & 0.0 & 0.13 & 0.05 & 0.04 & 0.00 & 0.00 \\
\hline \multicolumn{14}{|l|}{ ABD-4 } \\
\hline Target & 49.3 & 18.7 & 18.2 & 0.9 & 8.0 & 3.6 & 0.6 & 0.4 & 0.13 & 0.08 & 0.04 & - & - \\
\hline Measured & 48.5 & 18.6 & 18.6 & 0.9 & 7.9 & 4.0 & 0.6 & 0.4 & 0.14 & 0.10 & 0.04 & 0.00 & 0.04 \\
\hline \multicolumn{14}{|l|}{ ABD-5 } \\
\hline Target & 49.3 & 18.7 & 18.2 & 0.9 & 8.0 & 3.2 & 0.6 & 0.8 & 0.13 & 0.08 & 0.04 & - & - \\
\hline Measured & 49.4 & 18.6 & 18.3 & 0.9 & 7.6 & 3.3 & 0.6 & 0.8 & 0.14 & 0.11 & 0.04 & 0.03 & 0.06 \\
\hline \multicolumn{14}{|l|}{ ABD-6 } \\
\hline Target & 49.3 & 18.7 & 18.2 & 0.9 & 8.0 & 2.8 & 0.6 & 1.2 & 0.13 & 0.08 & 0.04 & - & - \\
\hline Measured & 48.1 & 18.9 & 18.8 & 0.9 & 8.1 & 2.9 & 0.6 & 1.2 & 0.12 & 0.11 & 0.04 & 0.03 & 0.06 \\
\hline
\end{tabular}

Composition measurements made using a combination of X-ray fluorescence spectroscopy, combustion infra-red method and inductively coupled plasma-optical emission spectroscopy. 


\section{RESULTS}

\section{A. Scanning Electron Microscopy}

Several SEM micrographs were taken at two magnifications from each of the studied alloys as shown in Figure 1. The micrographs taken at 500 times magnification revealed average grain sizes between 25 and $40 \mu \mathrm{m}$, which was within the target size range selected for a balance between yield strength, creep strength, and crack propagation resistance. Serrated grain boundaries and twinning were also observed in each alloy. At a magnification of 20,000 times, intragranular secondary and tertiary $\gamma^{\prime}$ precipitates were clearly visible, with the secondary precipitates occurring as a mix of spheroidal and cuboidal/octodendritic morphologies, and the smaller tertiary precipitates appearing to be spheroidal in all alloys. In contrast, the precipitates in the high $-\mathrm{Nb}$ alloy ABD-6 (Ti2.8Nb1.2) showed a unimodal distribution with a spheroidal morphology. No primary $\gamma^{\prime}$ was observed at the grain boundaries, so all precipitate analysis was performed within grains.

Further analysis was carried out using the ImageJ software package to determine the $\gamma^{\prime}$ cross-sectional area fraction and size distribution. Micrographs from several areas per sample were converted into 8-bit grayscale images, from which brightness histograms were created showing two peaks representing the dark $\gamma$ matrix and lighter $\gamma^{\prime}$ precipitates. The $\gamma-\gamma^{\prime}$ interface was defined by selecting a threshold brightness value located at the local brightness minima between the two peaks to ensure consistency across the analyses. The ImageJ particle analysis tool was employed to measure the area of each detected precipitate in the thresholded images. The effect of noise was reduced by discounting precipitates with an area $<300 \mathrm{~nm}^{2}$ (equivalent diameter $19.5 \mathrm{~nm}$ ), which represents any precipitate covering $<9$ pixels of the SEM micrograph at 20,000 times magnification.

Individual precipitate areas were summed to find the total $\gamma^{\prime}$ cross-sectional area fraction for each micrograph. This can be considered to equal the precipitate volume fraction as long as Delesse-Rosiwal conditions are met, which requires the surface to lie on a two dimensional plane.$^{[32]}$ For this reason, the samples were kept unetched, and a low electron beam current was used to minimize interaction depth. Three micrographs were taken for each alloy, resulting in mean average $\gamma^{\prime}$ volume fractions of $48,48,43$, and 47 pct for Alloys ABD-2, 4, 5, and 6, respectively (as summarized in Table III). The individual precipitate areas were also used to determine the precipitate size distributions by converting particle cross-sectional area $(A)$ into an equivalent diameter $(d)$ using the formula $d=2 \sqrt{A / \pi}$. Figure 2 shows the total precipitate size distributions summed over all micrographs of each alloy. ABD-2, 4, and 5 alloys (with compositions Ti4.1Nb0, Ti3.6Nb0.4, and $\mathrm{Ti3} .2 \mathrm{Nb} 0.8$, respectively) all show a large peak at 40-nm equivalent diameter, which corresponds to the smallest tertiary $\gamma^{\prime}$ precipitates not discounted as noise. Secondary $\gamma^{\prime}$ precipitates appear to have a bimodal distribution with precipitates in ABD-2 and 4 averaging 140 or $260 \mathrm{~nm}$ diameter, while ABD-5 shows unimodal secondaries of average $180 \mathrm{~nm}$. The high- $\mathrm{Nb}$ alloy ABD-6 (Ti2.8Nb1.2) is the outlier here, with very few tertiary precipitates and a unimodal secondary distribution peak centered on $160 \mathrm{~nm}$.
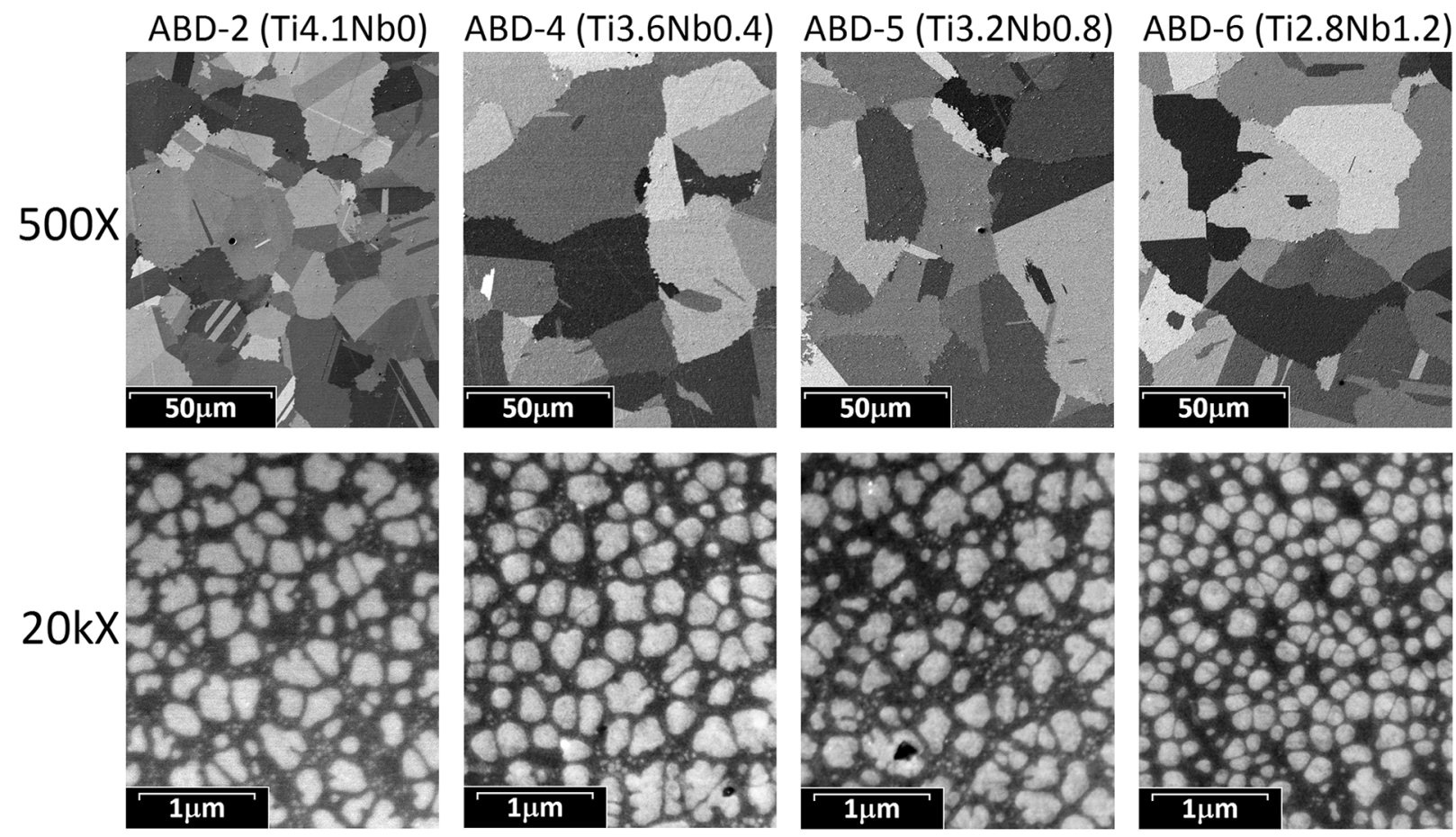

Fig. 1-SEM micrographs of ABD-series alloys at 500 times magnification showing the grain structure, and at 20,000 times magnification within a grain showing lighter $\gamma^{\prime}$ precipitates in the dark $\gamma$ matrix. 


\section{B. Atom Probe Tomography}

A total of eight successful atom probe experiments were run, comprising two specimens per alloy, with reconstructions varying in size from 26 to 105 million ions. The microstructure present in each of the alloys is shown in Figure 3, which shows 10-nm-thick sections clipped through the center of atom maps. Only Ti (blue) and $\mathrm{Cr}$ (pink) ions are shown as these elements partition strongly to $\gamma^{\prime}$ precipitates and $\gamma$ matrix phases respectively, allowing easy visual identification. The phase preference of each major constituent element is demonstrated in Figure 4, which consists of a 10-nm-thick slice clipped from a reconstruction of the ABD-4 alloy split into four pairs of elements. All elements were found to partition as expected, with $\mathrm{Ni}, \mathrm{Al}, \mathrm{Ta}, \mathrm{Ti}$, and $\mathrm{Nb}$ all partitioning to $\gamma^{\prime}$ precipitates while $\mathrm{Cr}$ and Co partition to the $\gamma$ matrix. Several generations of intergranular $\gamma^{\prime}$ precipitate were observed in reconstructions, occurring with a bimodal distribution of larger secondary $\gamma_{\text {II }}^{\prime}$ $(>100 \mathrm{~nm})$ and smaller spheroidal tertiary $\gamma_{\text {III }}^{\prime}(20$ to $60 \mathrm{~nm})$.

The overall composition for each sample was measured using the total ranged ion counts, from which a mean average composition was obtained for each alloy as shown in Table II. The boundary between $\gamma$ and $\gamma^{\prime}$ phases was defined with a 22.5 at. pct chromium isoconcentration surface, and the composition of each phase was found using a $10 \mathrm{~nm} \times 10 \mathrm{~nm} \times 10 \mathrm{~nm}$ region of interest far from this interface. The phase compositions presented in Table II are a weighted average of all occurrences of each phase across datasets from a particular alloy. Both secondary and tertiary $\gamma^{\prime}$ precipitates have been included in the average $\gamma^{\prime}$ phase composition as there was no observed correlation between precipitate size and composition.

The $\gamma-\gamma^{\prime}$ interface was also investigated for potential signs of segregation. Figure 5 shows two concentration profiles calculated as a function of the distance to a 22.5 at. pet $\mathrm{Cr}$ isosurface, also known as a proximity histogram (proxigram ${ }^{[33]}$ ). These were taken over a $10-\mathrm{nm}$ region crossing the interface in the ABD-5 alloy, separated into major ( $>5$ at. pct nominal) and minor $(<5$ at. pct nominal) constituent elements. There is a 2-nm-wide transition region between $\gamma$ and $\gamma^{\prime}$ phase compositions for most elements, with some notable exceptions. Ti and Ta do not reach equilibrium $\gamma^{\prime}$ concentration for several $\mathrm{nm}$ into the precipitates, while the $\mathrm{Cr}$ concentration entering the $\gamma$ matrix seems to plateau before rising again $2 \mathrm{~nm}$ from the interface. Additionally, $W$ enrichment can be seen directly at the $\gamma-\gamma^{\prime}$ interface, present at double the nominal $W$ concentration $\left(W_{\text {nom }}=0.8\right.$ at. pct). These features have been observed in multiple proxigrams across $\gamma-\gamma^{\prime}$ interfaces for each of the studied alloys.

Determination of phase chemistries allows an estimate of the $\gamma^{\prime}$ volume fraction $\phi_{\gamma^{\prime}}$ to be made using a derivation of the lever rule ${ }^{[34]}$ :

$$
C_{n}=\phi_{\gamma^{\prime}} C_{\gamma^{\prime}}+\left(1-\phi_{\gamma^{\prime}}\right) C_{\gamma},
$$

where $C_{n}, C_{\gamma}$, and $C_{\gamma^{\prime}}$ are the concentrations of an element present in the nominal alloy composition, and measured in the $\gamma$ and $\gamma^{\prime}$ phases, respectively. The $\gamma^{\prime}$

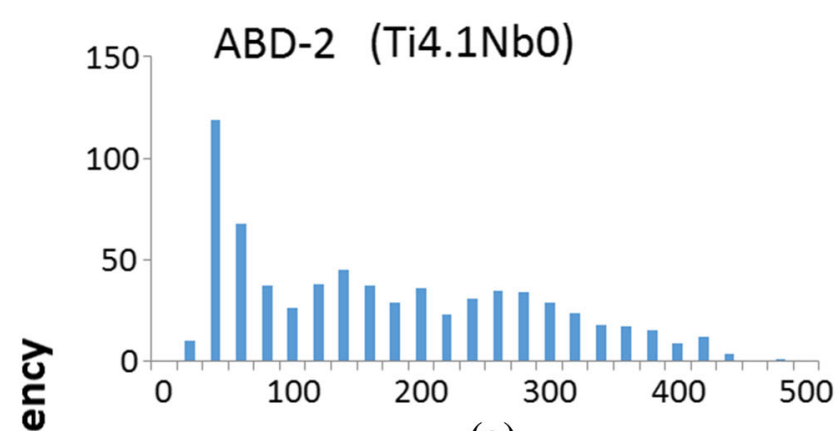

(a)

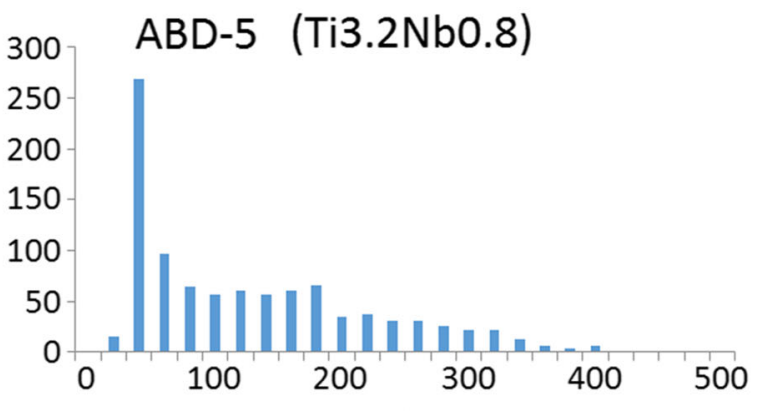

(c)

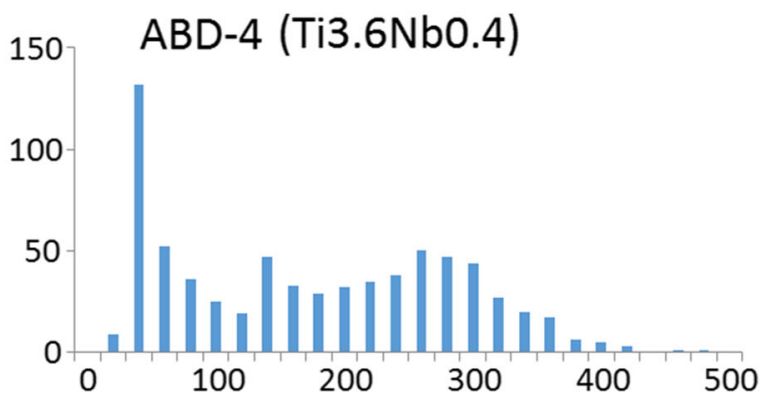

(b)

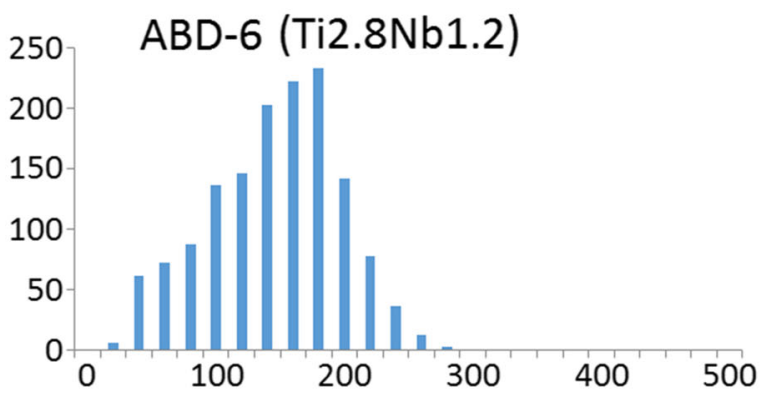

(d)

\section{$\gamma^{\prime}$ Equivalent Diameter $(\mathrm{nm})$}

Fig. 2-Images $(a)$ through $(d)$ show precipitate equivalent diameter distribution histograms summed over three separate SEM micrographs from alloys ABD-2, 4, 5, and 6, respectively. Diameters were grouped using a 20 -nm bin size. 


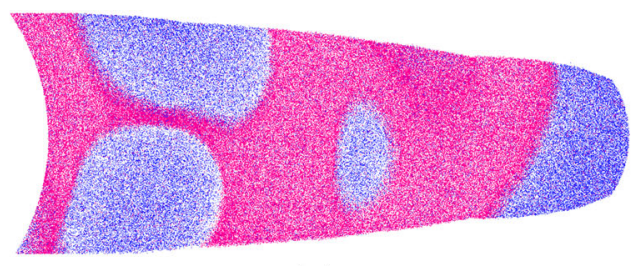

(a)

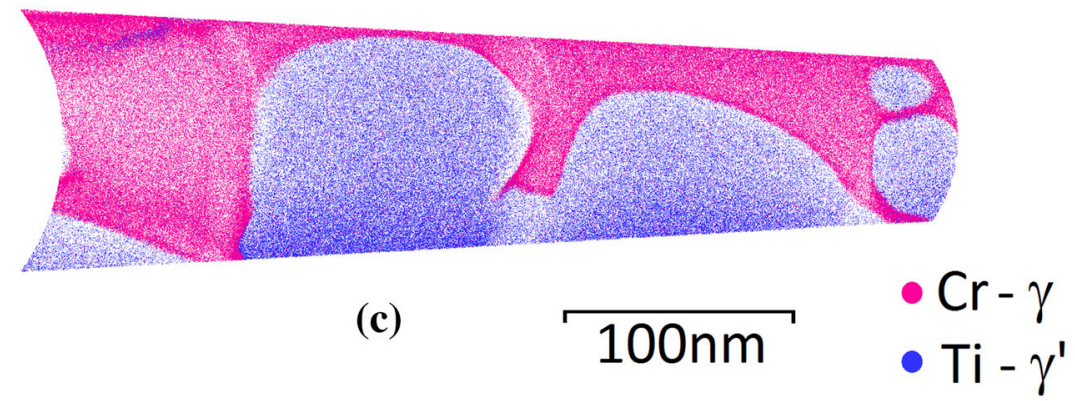

(b)

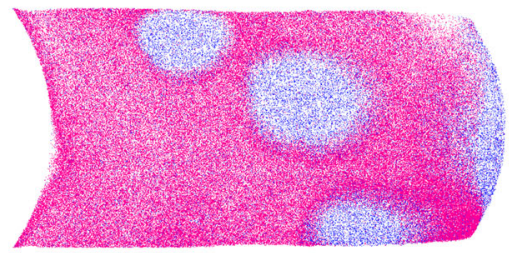

(d)

Fig. 3-Images (a) through (d) show 10-m-thick sections clipped from reconstructions of alloys ABD-2, 4, 5, and 6, respectively. Ti and Cr ions only are displayed to show $\gamma^{\prime}$ precipitate morphology.

volume fraction can be estimated by plotting $C_{n}-C_{\gamma} v s$ $C_{\gamma^{\prime}}-C_{\gamma}$ for each element and measuring the gradient of the best fit line, as shown in Figure 6. $\gamma^{\prime}$ volume fractions obtained using this technique is shown in Table III, combined with volume fractions observed during SEM and predictions made with Thermo-Calc using both TTNi8 and TCNi8 thermodynamic databases. The observed volume fraction values tend to lie very close to, or even between the two values predicted by Thermo-Calc using both databases.

Partitioning characteristics for each element are determined from Figure 6, with $\gamma^{\prime}$ forming elements located in the top right quadrant and $\gamma$ formers in the bottom left. Elements centered about the origin have been magnified in inset $(b)$. Most elements fall directly on the line of best fit, as the total composition is simply the sum of the $\gamma$ and $\gamma^{\prime}$ phase contributions. Exceptions to this include $C, B$, and $\mathrm{Zr}$ which are all known to segregate to grain boundaries, and $W$ which has been observed at elevated levels at $\gamma-\gamma^{\prime}$ interfaces. The phase partitioning preference of a particular element can be quantified using the partitioning coefficient $K^{\gamma^{\prime} / \gamma}$, defined as the concentration of that element in the $\gamma^{\prime}$ phase divided by the concentration in $\gamma$ phase. Consequently, high $K^{\gamma^{\prime} / \gamma}$ values indicate strong partitioning to $\gamma^{\prime}$ and near-zero $K^{\gamma^{\prime} / \gamma}$ values partition strongly to $\gamma$. Figure 7 displays the partitioning coefficients of $\mathrm{Ti}, \mathrm{Nb}, \mathrm{Cr}$ and Co across the four alloys, with $K^{\gamma^{\prime} / \gamma}$ values measured via APT (shown in blue) compared with values predicted by Thermo-Calc (red using TCNi8 database, green using TTNi8). The observed $K^{\gamma^{\prime} / \gamma}$ values were found to be consistently lower than values predicted using the TTNi8 database, resulting in a lower concentration of these elements present in the $\gamma^{\prime}$ phase. This is made up for by an increase in the observed $\gamma^{\prime}$ partitioning of $\mathrm{Ni}$. Predictions made using the TCNi8 database were much closer to observed values, but mostly showed opposing trends for $K^{\gamma^{\prime} / \gamma}$ vs $\mathrm{Nb}$ concentration. In addition, predicted $K^{\gamma^{\prime} / \gamma}$ values for $\mathrm{Ti}, \mathrm{Nb}$, and $\mathrm{Co}$ in alloy

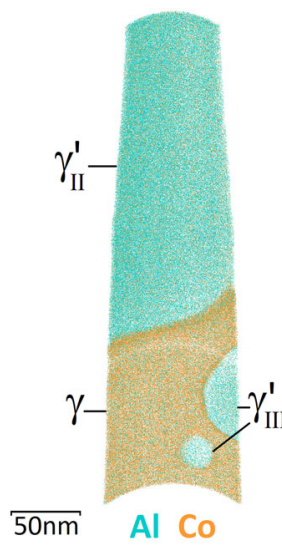

(a)

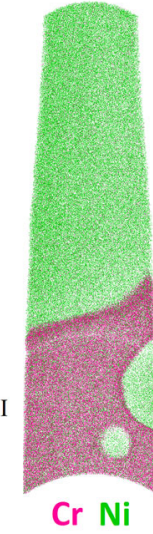

(b)

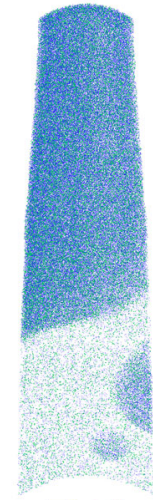

Ti N

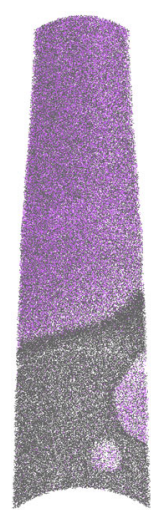

Ta $\mathbf{W}$

(d)
Fig. 4-Images $(a)$ through $(d)$ show pairs of elements present in a single 10-nm-thick section clipped from a reconstruction of alloy ABD-4 (Ti3.6Nb0.4). Both secondary and tertiary generations of $\gamma^{\prime}$ precipitate are clearly visible.

ABD-5 show a slight reduction in partitioning strength compared to the linear trendlines, which may result from the dip in $\mathrm{Al}$ concentration observed in the as-manufactured compositions in Table I.

\section{DISCUSSION}

\section{A. $\gamma^{\prime}$ Microstructure}

Precipitation of $\gamma^{\prime}$ phase is one of the most crucial strengthening mechanisms in these particular Ni-based superalloys, for which the volume fraction and size distribution are important factors. The alloys studied in this report were designed to have a $\gamma^{\prime}$ volume fraction of around 50 pct, which has been verified using both APT and SEM analysis as recorded in Table III. Interestingly, both experimental techniques and the two 
Table II. Total and Phase Compositions (Atomic Percent) as Measured by APT for Major Alloying Elements in ABD Series Superalloys

\begin{tabular}{|c|c|c|c|c|c|c|c|c|}
\hline Alloy & $\mathrm{Ni}$ & $\mathrm{Cr}$ & Co & $W$ & $\mathrm{Al}$ & $\mathrm{Ti}$ & $\mathrm{Ta}$ & $\mathrm{Nb}$ \\
\hline \multicolumn{9}{|l|}{ ABD-2 } \\
\hline Total & 49.3 & 17.3 & 17.2 & 0.8 & 8.9 & 4.9 & 0.6 & 0.0 \\
\hline$\gamma$ & 32.7 & 35.5 & 27.2 & 0.8 & 2.5 & 0.3 & 0.1 & 0.0 \\
\hline$\gamma^{\prime}$ & 65.3 & 1.9 & 8.6 & 0.8 & 13.6 & 8.2 & 1.2 & 0.0 \\
\hline \multicolumn{9}{|l|}{ ABD-4 } \\
\hline Total & 48.4 & 19.2 & 18.6 & 0.9 & 7.8 & 3.6 & 0.5 & 0.3 \\
\hline$\gamma$ & 34.2 & 33.8 & 27.0 & 1.1 & 2.8 & 0.4 & 0.1 & 0.1 \\
\hline$\gamma^{\prime}$ & 65.3 & 2.0 & 8.7 & 0.9 & 13.6 & 7.0 & 1.0 & 0.6 \\
\hline \multicolumn{9}{|l|}{ ABD-5 } \\
\hline Total & 47.4 & 20.5 & 19.4 & 0.8 & 7.0 & 2.7 & 0.5 & 0.6 \\
\hline$\gamma$ & 36.6 & 32.3 & 26.4 & 0.9 & 2.5 & 0.4 & 0.1 & 0.2 \\
\hline$\gamma^{\prime}$ & 65.1 & 2.1 & 8.6 & 0.9 & 13.8 & 6.2 & 1.1 & 1.3 \\
\hline \multicolumn{9}{|l|}{ ABD-6 } \\
\hline Total & 47.0 & 21.1 & 19.1 & 0.9 & 7.6 & 2.6 & 0.5 & 0.9 \\
\hline$\gamma$ & 33.7 & 35.1 & 25.9 & 1.1 & 2.6 & 0.3 & 0.1 & 0.3 \\
\hline$\gamma^{\prime}$ & 64.7 & 2.1 & 8.8 & 0.7 & 14.3 & 5.7 & 1.2 & 1.9 \\
\hline
\end{tabular}

thermodynamic databases predict a slightly lower $\gamma^{\prime}$ volume fraction for alloy ABD-5 compared to the other alloys. It is tempting to attribute this lower $\gamma^{\prime}$ volume fraction to the slight $\mathrm{Al}$ deficit seen in the as-manufactured compositions in Table I (7.6 at. pct measured vs 8.0 at. pct target), which could lead to a reduction in the nominally $\mathrm{Ni}_{3} \mathrm{Al} \gamma^{\prime}$ phase. However, the difference in $\gamma^{\prime}$ volume fraction is an order of magnitude larger than the Al compositional deficit, so no solid conclusions can be drawn at this time.

Most of the ABD alloys express this $\gamma^{\prime}$ volume fraction as a mixture of small tertiary precipitates in addition to a bimodal distribution of secondaries, which is backed up by research on the same ABD-series alloys carried out by Hisazawa et al. ${ }^{[35]}$ In the as-received state, the alloys were reported to have a very small fraction of primary $\gamma^{\prime}$ due to the super-solvus heat treatment regime, plus secondaries in the $\sim 200 \mathrm{~nm}$ size range and tertiaries $<50 \mathrm{~nm}$, which almost perfectly matches the SEM observations and size distributions shown in Figures 1 and 2. The only discrepancy involves the high-Nb ABD-6 alloy, which was observed in this study to have a unimodal size distribution with little differentiation between secondary and tertiary precipitates. It seems unlikely that this can be directly linked to the increased $\mathrm{Ti} / \mathrm{Nb}$ ratio in the $\mathrm{ABD}-6$ alloy, as Hisazawa et al. saw no correlation between $\mathrm{Ti} / \mathrm{Nb}$ ratio and size distributions, likely due to the similar diffusion rates of $\mathrm{Ti}$ and $\mathrm{Nb}$ leading to similar nucleation and growth kinetics. The unimodal distribution combined with the change to a more spherical morphology indicates that the ABD-6 sample has undergone higher rates of growth than nucleation during heat treatment, possibly due to its position within the forging.

\section{B. Interface Chemistry}

One of the unexpected results from this experiment was the discovery of $W$ enrichment at $\gamma-\gamma^{\prime}$ interfaces. The first indication came from the Lever rule plots used to calculate $\gamma^{\prime}$ volume fraction (an example of which is shown in Figure 6), where the plotted positions of $W, C$, $B$, and $\mathrm{Zr}$ data points did not lie directly on the best fit line. $C, B$, and $Z \mathrm{r}$ are known to preferentially segregate to grain boundaries, so investigation of interface regions was carried out. None of these grain boundary segregants were found, but a thin shell of $W$-enriched material surrounding $\gamma^{\prime}$ precipitates was revealed. This behavior has also been seen by Amouyal et al. in ME-9 alloy ${ }^{[36]}$ and a single crystal directionally solidified superalloy. ${ }^{[37]}$ It is unknown if this behavior is due to preferential segregation, or rejection of $W$ during $\gamma^{\prime}$ formation. The shape of the $W$ concentration profile over the $\gamma-\gamma^{\prime}$ interface is similar to the 'bow-wave' profile seen by Warren et al. ${ }^{[38]}$ for Re in single-crystal RR3000, which was attributed to diffusion-limited rejection of solute. This could also apply to $W$, which has been shown by Karunaratne et al. ${ }^{[39]}$ to have a similar, but slightly larger interdiffusion coefficient to Re through $\gamma$ phase.

The Ti and Ta concentration profiles were also found to be non-uniform over the $\gamma-\gamma^{\prime}$ interface, with both elements continuously increasing in concentration up to $5 \mathrm{~nm}$ within the $\gamma^{\prime}$ precipitates. A similar effect was observed for Ti, Ta, and Hf in the RR1000 alloy as seen by Bagot et al.. ${ }^{[40]}$ where it was attributed to the large lattice misfits for these elements as estimated using Vegard's Law. ${ }^{[1]} \mathrm{Cr}$ concentration profiles were also found to be non-uniform heading into the $\gamma$ matrix phase, showing a trend of rising to a plateau concentration of roughly 30 at. pct, before rising another 2 to 4 at. pct $2 \mathrm{~nm}$ from the interface. This trend was repeated across 29 of the 32 analyzed $\gamma-\gamma^{\prime}$ interfaces. The origin of this slight non-uniformity requires further detailed study, as it is possible that it may be a field evaporation artefact caused by moving through the interface.

\section{Alloy Composition/Phase Chemistry}

In addition to volume fraction, control of alloy composition is critical to ensuring a good balance of properties within both the matrix and precipitates. The 


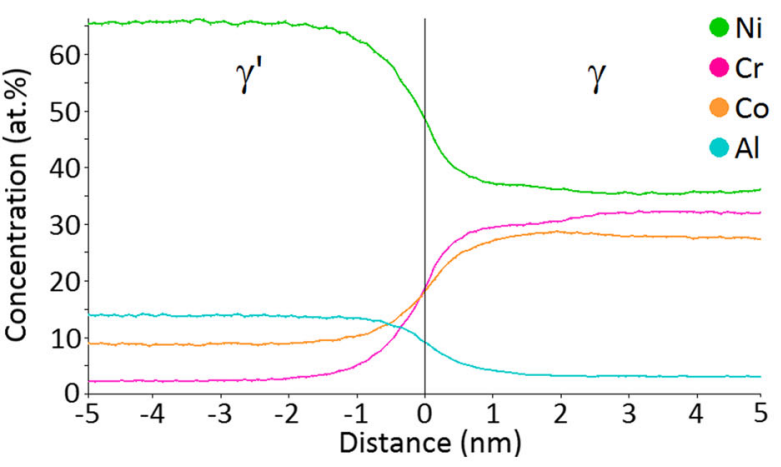

(a)

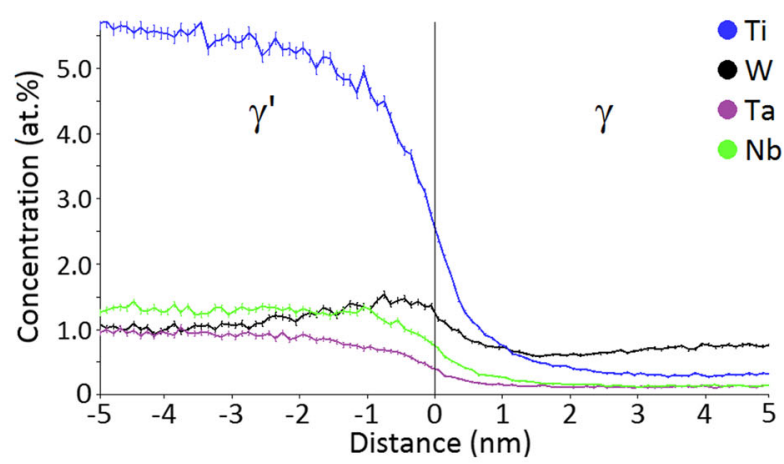

(b)

Fig. 5-Proxigrams showing concentration profiles across a secondary $\gamma^{\prime}-\gamma$ interface defined by a 22.5 at. pct Cr isosurface in the ABD-5 alloy (Ti3.2Nb0.8). Graphs $(a)$ and $(b)$ show major ( $>5$ at. pct) and minor $(<5$ at. pct) constituents respectively.

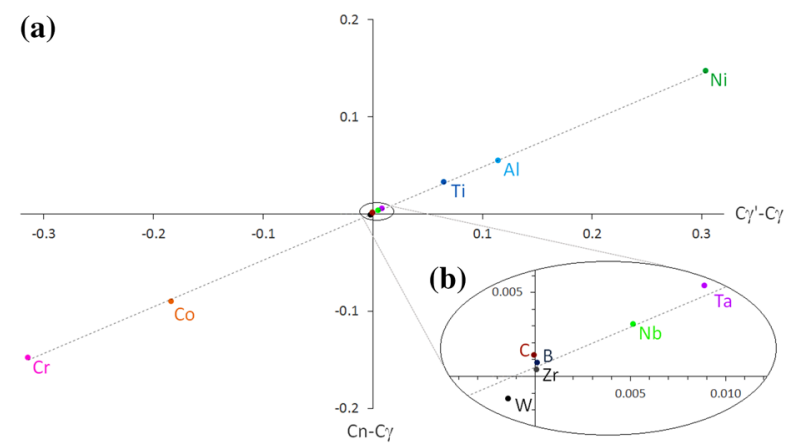

Fig. 6-Lever rule derivation plot for the ABD-4 alloy (Ti3.6Nb0.4) shown in $(a)$. The line of best fit gradient equates to $\gamma^{\prime}$ volume fraction (48 pct). Inset $(b)$ shows an enlarged view of the elements centered about the origin.

Table III. $\gamma^{\prime}$ Volume Percentages Predicted Using Two

Different Thermodynamic Models TTNi8 and TCNi8, Compared Against Observations Made via SEM and APT

\begin{tabular}{lcccc}
\hline Alloy & TTNi8 & TCNi8 & SEM & APT \\
\hline ABD-2 & 49.7 & 46.9 & 48.3 & 50.0 \\
ABD-4 & 50.2 & 46.8 & 48.0 & 48.1 \\
ABD-5 & 46.6 & 42.8 & 42.6 & 45.4 \\
ABD-6 & 48.9 & 44.3 & 46.5 & 49.2 \\
\hline
\end{tabular}

example of reduced $\mathrm{Al}$ content in the as-manufactured ABD-5 composition mentioned above has slight knock-on effects for both precipitate volume fraction (Table III), and the partitioning ratios of other $\gamma^{\prime}$-forming elements (Figure 7), showing how slight changes can influence these chemically complex systems. One of the reasons for creating these alloys is to assess whether $\mathrm{Ti}$ can be swapped out for $\mathrm{Nb}$ without causing major changes to the alloy properties. Both $\mathrm{Ti}$ and $\mathrm{Nb}$ promote high-temperature strength by increasing APB energy in the $\gamma^{\prime}$ phase ${ }^{[6,7]}$ but the effect is lessened if they partition to the matrix, which highlights the importance of their partitioning characteristics. $\mathrm{Cr}$ and $\mathrm{Co}$ fulfil a similar role in the matrix by providing solid solution strengthening. The partitioning graphs shown in
Figure 7 for these four elements show that the addition of $\mathrm{Nb}$ does have a minor effect, with Ti partitioning less strongly to $\gamma^{\prime}$, while $\mathrm{Nb}, \mathrm{Cr}$, and Co migrate into the $\gamma^{\prime}$ precipitates.

These results have then been compared with the partitioning coefficients predicted by Thermo-Calc using two different databases-TTNi8 (Thermo-Tech) and TCNi8 (Thermo-Calc). The TTNi8 values tend to overestimate the $\gamma^{\prime}$ preference exhibited by $\mathrm{Ti}, \mathrm{Nb}, \mathrm{Cr}$, and Co. This mirrors similar findings relating to thermodynamic predictions of $\mathrm{Nb}$ partitioning by Antonov et al. ${ }^{[8]}$ and Miller et al., ${ }^{[41]}$ who notes that overestimation of $\mathrm{Nb} \gamma^{\prime}$ partitioning can lead to inflated strength predictions.

The $K^{\gamma^{\prime} / \gamma}$ vs $\mathrm{Nb}$ pct trendlines also oppose the observed trends for the elements $\mathrm{Nb}, \mathrm{Cr}$, and $\mathrm{Co}$. The TCNi8 predictions fall much closer to the observed partitioning values, but still show opposing trends for $\mathrm{Ti}, \mathrm{Cr}$, and Co. These discrepancies may be due to the assumption of thermodynamic equilibrium which is never reached due to material inhomogeneities or unaccounted kinetics and diffusion. ${ }^{[41]}$ Thermodynamic modeling is a powerful tool which gives us the ability to perform billions of potential experiments in silico, but it must be acknowledged that these are still just predictions, and used accordingly. However, this study has shown that careful, methodical use of APT can play a key role in benchmarking the results from theoretical predictions, as also recently demonstrated on in-service alloys. ${ }^{[40]}$ This combination of APT and modeling thus offers a robust, general methodology which should be considered in alloy design.

\section{SUMMARY AND CONCLUSIONS}

1. SEM micrograph analyses have shown that Alloys ABD-2 (Ti4.1Nb0), ABD-4 (Ti3.6Nb0.4), and ABD-5 (Ti3.2Nb0.8) form both secondary and tertiary intragranular $\gamma^{\prime}$ precipitates, with a bimodal distribution of secondaries. The high- $\mathrm{Nb}$ alloy ABD-6 (Ti2.8Nb1.2) was shown to have a unimodal secondary $\gamma^{\prime}$ distribution with spheroidal morphology for this particular sample. 


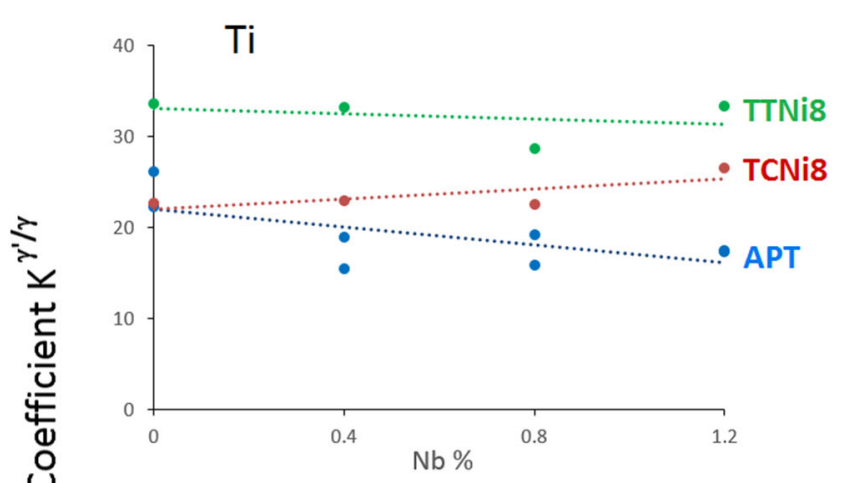

(a)

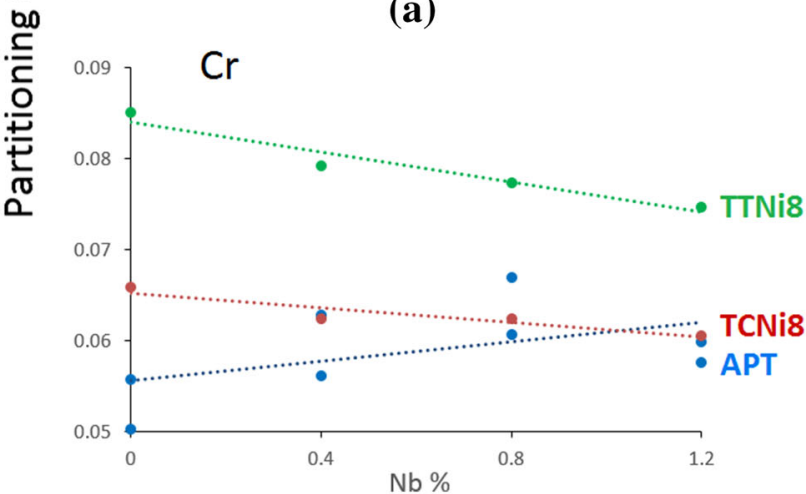

(c)

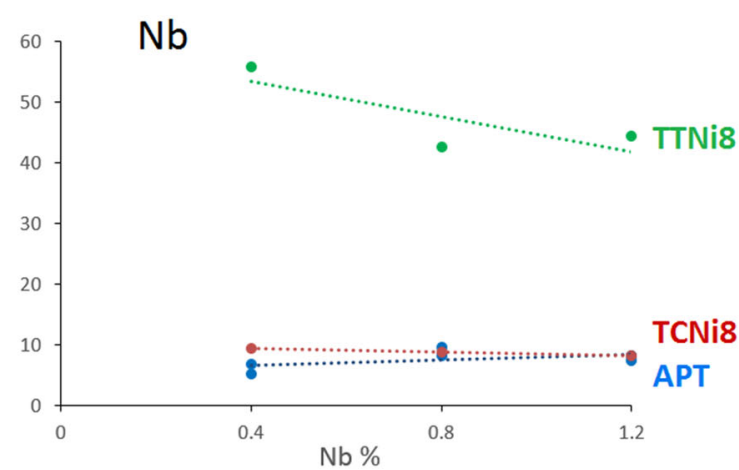

(b)

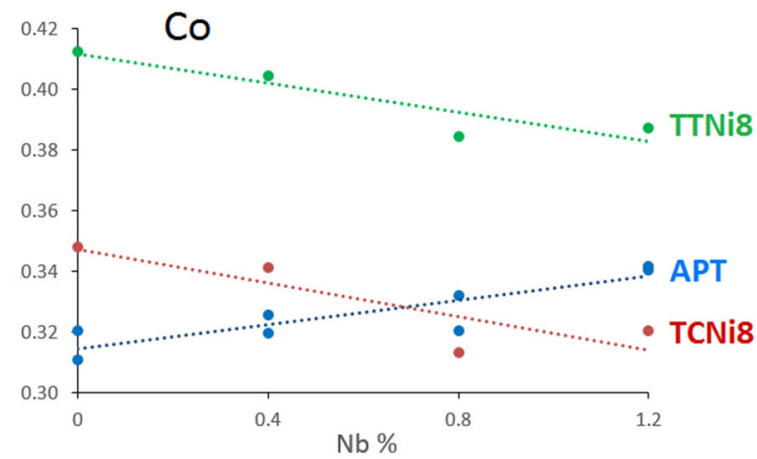

(d)

Fig. 7-Partitioning coefficients of $\mathrm{Ti}, \mathrm{Nb}, \mathrm{Cr}$, and Co shown in $(a)$ through $(d)$ respectively, as a function of $\mathrm{Nb}$ at. pct representing the four alloys studied. Atom probe data from two samples of each alloy are represented in blue, with thermodynamic predictions made using TTNi8 (green) and TCNi8 (red) databases (Color figure online).

2. Intragranular precipitate volume fractions have been estimated using cross-sectional areal fractions found via ImageJ analysis of SEM micrographs. The observed volume fractions match values found via APT using lever rule analysis, and show good correlation with Thermo-Calc predictions made using both TTNi8 and TCNi8 databases.

3. Atom-Probe Tomography has been used to create representative $3 \mathrm{D}$ maps of the microstructure and quantitatively measure the compositions of $\gamma$ phase matrix and microscale $\gamma^{\prime}$ precipitates, which compare favorably with both composition predictions from Thermo-Calc.

4. Both secondary and tertiary generations of $\gamma$ ' precipitates were found to have similar compositions, with no apparent size-dependence. $W$ was observed to segregate to $\gamma-\gamma^{\prime}$ interfaces of multiple $\gamma^{\prime}$ precipitates across several datasets, possibly due to diffusion-limited pileup during $\gamma^{\prime}$ phase growth.

5. All elements were found to partition to the phases expected, although partitioning coefficients for $\mathrm{Ti}$, $\mathrm{Nb}, \mathrm{Cr}$, and Co were found to differ from predicted values. $K^{\gamma^{\prime} / \gamma}$ values predicted using the TTNi8 database tended to overestimate $\gamma^{\prime}$ partitioning behavior, whilst values predicted using the $\mathrm{TCNi} 8$ database were much closer but often showed opposing $K^{\gamma^{\prime} / \gamma}$ vs Ti:Nb trends.

\section{ACKNOWLEDGMENTS}

The authors would like to acknowledge the financial support of the UK Engineering and Physical Sciences Research Council (EPSRC) and the Rolls-Royce Strategic Partnership in Structural Metallic Systems for Gas Turbine Applications EP/H022309/1 and EP/ H500375/1 and Rolls-Royce plc for the provision of material. The Oxford Atom Probe facility has been funded by the EPSRC Grant EP/D077664/1. The research materials supporting this publication can be accessed by contacting the Oxford Research Archive at ora@bodleian.ox.ac.uk.

\section{OPEN ACCESS}

This article is distributed under the terms of the Creative Commons Attribution 4.0 International License (http://creativecommons.org/licenses/by/4.0/), which permits unrestricted use, distribution, and reproduction in any medium, provided you give appropriate credit to the original author(s) and the source, provide a link to the Creative Commons license, and indicate if changes were made. 


\section{REFERENCES}

1. R.C. Reed: The Superalloys Fundamentals and Applications, Cambridge University Press, Cambridge, 2006.

2. M. McLean: Philos. Trans. R. Soc. Lond. A., 1995, vol. 351, pp. 419-33.

3. J.C. Williams and E.A. Starke: Acta Mater., 2003, vol. 51, pp. $5775-99$.

4. T.M. Pollock and S. Tin: J. Propuls. Power., 2006, vol. 22, pp. $361-74$.

5. A. Pineau and S.D. Antolovich: Eng. Fail. Anal., 2009, vol. 16, pp. 2668-97.

6. T.M. Pollock and R.D. Field: Dislocat. Solids., 2002, vol. 11, pp. 547-618.

7. E.C. Guo and F.J. Ma: in Superalloys 1980., 1980, pp. 431-38.

8. S. Antonov, M. Detrois, D. Isheim, D. Seidman, R.C. Helmink, R.L. Goetz, E. Sun, and S. Tin: Mater. Des., 2015, vol. 86, pp. 649-55.

9. H.S. Kitaguchi, H.Y. Li, H.E. Evans, R.G. Ding, I.P. Jones, G. Baxter, and P. Bowen: Acta Mater., 2013, vol. 61, pp. 1968-81.

10. M. Detrois, R.C. Helmink, and S. Tin: Metall. Mater. Trans. A., 2014, vol. 45A, pp. 5332-43.

11. G.K. Bouse: Miner. Met. Mater. Soc., 1996, pp. 163-72.

12. M. Durand-Charre: The Microstructure of Superalloys, CRC Press, Boca Raton, 1998.

13. J.H. Chen, P.M. Rogers, and J.A. Little: Oxid. Met., 1997, vol. 47, pp. 381-410.

14. H. Nagai and M. Okabayashi: Trans. Jpn. Inst. Met., 1981, vol. 22, pp. $691-98$

15. R.C. Reed, T. Tao, and N. Warnken: Acta Mater., 2009, vol. 57, pp. 5898-5913.

16. D.J. Crudden, B. Raeisinia, N. Warnken, and R.C. Reed: Metall. Mater. Trans. A., 2012, vol. 44A, pp. 2418-30.

17. B. Gault, M.P. Moody, J.M. Cairney, and S.P. Ringer: Atom Probe Microscopy, Springer, New York, 2012, vol. 160.

18. D. Blavette, E. Cadel, and B. Deconihout: Mater. Charact., 2000, vol. 44 , pp. $133-57$.

19. D. Blavette, E. Cadel, C. Pareige, B. Deconihout, and P. Caron: Microsc. Microanal., 2007, vol. 13, pp. 464-83.

20. M.K. Miller: Micron., 2001, vol. 32, pp. 757-64.

21. D.N. Seidman, C.K. Sudbrack, and K.E. Yoon: JOM., 2006, vol. 58 , pp. 34-39.
22. S. Chambreland, A. Walder, and D. Blavette: Acta Metall., 1988, vol. 36, pp. 3205-15.

23. S.S. Babu, M.K. Miller, J.M. Vitek, and S.A. David: Acta Mater., 2001, vol. 49, pp. 4149-60.

24. J. Tiley, G.B. Viswanathan, R. Srinivasan, R. Banerjee, D.M. Dimiduk, and H.L. Fraser: Acta Mater., 2009, vol. 57, pp. 2538-49.

25. J.Y. Hwang, R. Banerjee, J. Tiley, R. Srinivasan, G.B. Viswanathan, and H.L. Fraser: Metall. Mater. Trans. A., 2009, vol. 40A, pp. 24-35.

26. X.P. Tan, D. Mangelinck, C. Perrin-Pellegrino, L. Rougier, C.-A. Gandin, A. Jacot, D. Ponsen, and V. Jaquet: J. Alloys Compd., 2014, vol. 611, pp. 389-94.

27. R. Reed, D. Crudden, B. Raeisinia, and M.C. Hardy: Nickel Based Alloy Composition, European Patent Office EP2894234, 2015.

28. W. Rasband, ImageJ, http://imagej.nih.gov/ij/. Accessed 01 Jan 2017.

29. D. Haley, APTtools, http://apttools.sourceforge.net/, Accessed 01 Jan 2017

30. D. Haley, P. Choi, and D. Raabe: Ultramicroscopy., 2015, vol. 159 , pp. $338-45$.

31. D.M. Collins, D.J. Crudden, E. Alabort, T. Connolley, and R.C. Reed: Acta Mater., 2015, vol. 94, pp. 244-56.

32. J.J. Friel: Practical Guide to Image Analysis, ASM International, Almere, 2000

33. O.C. Hellman, J.A. Vandenbroucke, J. Rüsing, D. Isheim, and D.N. Seidman: Microsc. Microanal., 2000, vol. 6, pp. 437-44.

34. D. Blavette, P. Caron, and T. Khan: Superalloys., 1988, vol. 1988, pp. $305-14$

35. H. Hisazawa, Y. Terada, F. Adziman, D. Crudden, D. Collins, D. Armstrong, and R. Reed: Metals (Basel)., 2017, vol. 7, pp. 71-81.

36. Y. Amouyal, Z. Mao, and D.N. Seidman: Acta Mater., 2014, vol. 74, pp. 296-308.

37. Y. Amouyal, Z. Mao, and D.N. Seidman: Appl. Phys. Lett., 2008, vol. 93 , pp. $1-4$.

38. P.J. Warren, A. Cerezo, and G.D.W. Smith: Mater. Sci. Eng. A., 1998, vol. 250, pp. 88-92.

39. M.S.A. Karunaratne, P. Carter, and R.C. Reed: Mater. Sci. Eng. A., 2000, vol. 281, pp. 229-33.

40. P.A.J. Bagot, O.B.W. Silk, J.O. Douglas, S. Pedrazzini, D.J. Crudden, T.L. Martin, M.C. Hardy, M.P. Moody, and R.C. Reed: Acta Mater., 2017, vol. 125, pp. 156-65.

41. M.K. Miller, S.S. Babu, and M.G. Burke: Mater. Sci. Eng. A., 2002, vol. 327 , pp. $84-88$ 